BACTRRLAL UTIUTATION OF POLYSACOHARIDES ('MUCINS') IN SALIVA INCUBATED AT $37^{\circ} \mathrm{C}$.

\begin{tabular}{|c|c|c|c|c|c|}
\hline \multirow{2}{*}{$\begin{array}{c}\text { Time } \\
\text { (in hr.) }\end{array}$} & \multicolumn{5}{c|}{ Glucosamine hydrochloride (mgm./ml.) } \\
& H.J. & A.P. & L.C. & H.F.H. & D.C. \\
\hline 0 & 0.55 & 0.43 & 0.42 & 0.21 & 0.27 \\
24 & 0.42 & -10 & 0.22 & 0.09 & 0.12 \\
48 & 0.18 & 0.10 & 0.20 & 0.01 & 0.05 \\
72 & 0.08 & 0.09 & - & - & - \\
\hline
\end{tabular}

table). The rate of disappearance of glucosamine was, in fact, shown to be paralleled by that of both total sugar and reducing sugar, the latter being measured after acid hydrolysis.

The utilization of glucosamine was completely inhibited by bactericidal substances such as phenol, toluene, thymol and penicillin, or by heating to $100^{\circ}$ for five minutes. There was partial inhibition by 1 per cent glucose or maltose, but not by powdered solid starch.

In the presence of the bactericides, a substance accumulated in some samples which reacted as $\mathrm{N}$-acetyl glucosamine in the Morgan and Elson ${ }^{3}$ test. 'This substance was diffusible through 'Cellophane' and its liberation was due to enzymes associated with the cellular material present in the saliva, and not to enzymes formed by the salivary glands. The relation of the observed hydrolysis of the polysaccharides to the breakdown of the 'blood group sub. stances' ${ }^{4,5,6}$ present in relatively high concentration in the saliva of 'secretors' ${ }^{\text {' }}$ is of interest.

The significance of these observations in connexion with the well-known pathological conditions of the mouth is, of course, unknown; but it is clear that organisms in stagnation areas would be able to obtain considerable amounts of fermentable material by breaking down the salivary mucins.

I should like to express my thanks to $\mathrm{Mr}$. A. Parkinson for his enthusiastic and competent technical assistance during the work.

Biological Research Department,

Dental School and Hospital,

University of Leeds.

1 Elson, L. A., and Morgan, W. T. J., Biochem. J., 27, 1824 (1933)

Sørensen, M., and Haaguard, G., Biochem. Z., 260, 247 (1933).

Morgan, W. T. J., and Elson, L. A., Biochem. J., 28, 988 (1934).

- Schiff, F., and Weiler, G., Biochem. Z., 235, 454; 239, 489 (1931).

- Morgan, W. T. J., Nature, 158, 759 (1946).

- Hartman, G.. "Group Antigens in Human Organs" (Saabye and Christensen, Denmark, 1941).

\section{A Possible Relation Between the Action of Clover Juice on Isolated Muscle and 'Bloat' in Cattle}

THE disturbance known as bloat, or hoven, in cattle arises through the inability of the animals to expel the gases formed in the rumen. Bloat can be expected when cattle graze young luscious clover or lucerne, but occasionally young grass can also cause the trouble.

A favoured view of the cause of bloat is that the muscles of the rumen wall lapse into relative immobility in the absence of adequate fibre in the diet and so fail to urge the gases to the œesophagus. Another view is that an allergic shock, resulting from some food constituent, may cause a spasm of the smooth muscle of the cardiac sphincter and so prevent escape of gas. In view of the possible association between bloat and rumen muscle activity, experiments were carried out to see if various herbage juices have any action on isolated smooth muscle.

Using rabbit intestine in Tyrode solution, twelve juices of legumes ( $S 100$ white clover, wild white clover and lucerne) and nine grass juices were tested. One $S 100$ white clover was taken from a field in which two cows had just died through bloat. Very marked differences were obtained: the legume juices, when added in quantities of 0.7-2 ml. to a Tyrode bath of $55 \mathrm{ml}$. capacity, caused a rapid and very marked diminution in the amplitude and fre. quency of the gut movements. In some cases $2 \mathrm{ml}$. juice almost completely arrested the movements. At times this partial paralysis was accompanied by a relaxation of the muscle, as shown by a slight fall in the level of the tracing, or was occasionally preceded by a brief stimulation of movement.

Juices from two permanent pastures (one an irrigated pasture) gave effects resembling the clover, although the frequency of movements was not reduced. All other grass juices, from permanent grass and leys, gave quite different tracings. 1-2 ml. generally produced stimulation, but movements were occasionally uneven. The two types of effect are shown in the accompanying photograph.

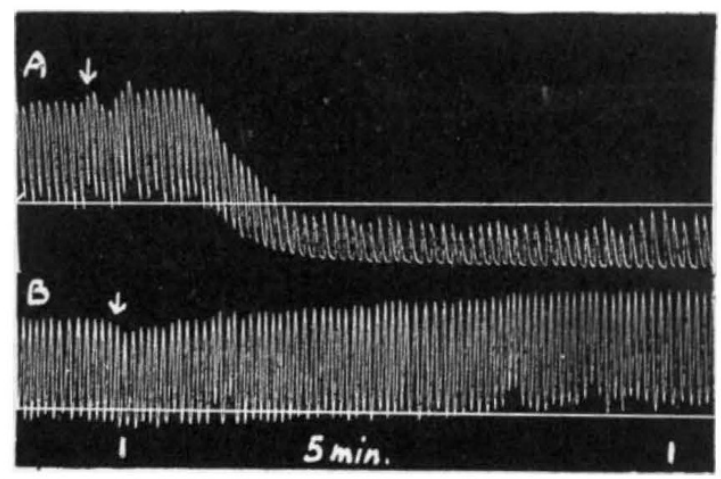

$A$, CLOVER JUICE ; $B$, GRASS JUTCE

Tests have shown it is unlikely that inorganic ions are responsible for the clover effect, and attempts are being made to separate the substance or substances responsible.

Heat only partially reduces the effect, and the loss may be caused by absorption of material on protein precipitated by the heating. The active substance passes through a 'Cellophane' membrane. An alkaloid fraction showed no effect.

Preliminary tests have indicated that the addition of very small quantities of adrenalin to muscle affected by clover juice can cause recovery after a brief period. This observation needs confirming, but it is of interest since injections of adrenalin are commonly given to treat bloat in cattle.

The peculiar effect of clover juice may, or may not, be of significance in bloat; but further work on the isolation of the substance or substances appears justified. If this is achieved, direct animal confirmatory tests will be possible.

W. S. Ferguson

Imperial Chemical Industries, Ltd.,

Jealott's Hill Research Station, Bracknell, Berks.

Feb. 3. 